\title{
IgY antibodies in human nutrition for disease prevention
}

\author{
Sandra Müller ${ }^{1}$, Andreas Schubert ${ }^{1}$, Julia Zajac ${ }^{1}$, Terry Dyck² and Christopher Oelkrug ${ }^{1,3^{*}}$
}

\begin{abstract}
Oral administration of preformed specific antibodies is an attractive approach against infections of the digestive system in humans and animals in times of increasing antibiotic resistances. Previous studies showed a positive effect of egg yolk IgY antibodies on bacterial intoxications in animals and humans. Immunization of chickens with specific antigens offers the possibility to create various forms of antibodies. Research shows that orally applied IgY's isolated from egg yolks can passively cure or prevent diseases of the digestive system. The use of these alternative therapeutic drugs provides further advantages: (1) The production of IgY's is a non-invasive alternative to current methods; (2) The keeping of chickens is inexpensive; (3) The animals are easy to handle; (4) It avoids repetitive bleeding of laboratory animals; (5) It is also very cost effective regarding the high IgY concentration within the egg yolk. Novel targets of these antigen specific antibodies are Helicobacter pylori and also molecules involved in signaling pathways in gastric cancer. Furthermore, also dental caries causing bacteria like Streptococcus mutans or opportunistic Pseudomonas aeruginosa in cystic fibrosis patients are possible targets. Therefore, IgY's included in food for human consumption may be able to prevent or cure human diseases.
\end{abstract}

Keywords: IgY, Egg yolk immunoglobulin, Nutrition, Oral passive immunization, Passive immunity

\section{The avian immune system}

To protect the host against invading microorganisms and exogenous antigens, the avian species have also developed an immune system similar to mammals. The avian immune system consists of primary and secondary lymphoid organs. Thymus, located in the neck and Bursa Fabricius, located adjacent to the cloaca, are primary lymphoid organs. Secondary organs are spleen, caecal tonsils, Harderian gland, bone marrow, lymph nodes, and various lymphoid tissues e.g. lymphoid tissues associated with mucosal surfaces (MALT); including bronchialassociated lymphoid tissues (BALT), gut associated lymphoid tissues (GALT) and conjunctival associated lymphoid tissues (CALT). The thymus is considered to be the primary lymphoid organ for T-cell differentiation and the antibody-synthesizing B-cells are formed in the Bursa of Fabricius, an organ which is unique in birds $[1,2]$. The

\footnotetext{
* Correspondence: christopher.oelkrug@izi.fraunhofer.de

'Fraunhofer Institute for Cell Therapy and Immunology (IZI), Perlickstraße 1, 04103 Leipzig, Germany

${ }^{3}$ Fraunhofer Project Centre for Biomedical Engineering and Advanced Manufacturing, McMaster University, Hamilton, Canada

Full list of author information is available at the end of the article
}

plasma cell proliferation and memory B-cells are situated within the spleen [3].

The avian immune system basically consists of two types: first the innate, non-specific system and second the acquired, specific system. The latter is mainly characterized by specificity and memory. This system can be distinguished into the cellular and non-cellular immune response, once again.

The cellular response can be defined as those cells that react with a high specificity to their specific antigen but not including the cells involved in antibody production. T-lymphocytes, as part of the cellular branch, recognize processed antigens on antigen-presenting macrophages. Among other tasks, T-cells are able to enhance or suppress the activity of B-cells, macrophages and T-helper cells. Further T-cells can directly destroy foreign organisms [4].

The non-cellular, also referred to as the humoral response, includes plasma proteins, e.g. immunoglobulins that passively circulate in blood or lymph, and antibody producing B-lymphocytes. These cells are formed in the embryonic liver, yolk sack and bone marrow. After maturation in the Bursa Fabricius, B-cells move to the blood, 
spleen, caecal tonsils, bone-marrow, Harderian gland, and thymus. T-helper cells are able to activate B-cells into plasmocytes. These plasmocytes are then able to secrete antibodies (immunoglobulins) which are highly specific for binding antigens. After re-exposing a chicken to the same antigen a memory effect occurs, involving an increased antibody production at a faster rate [5].

\section{Immunoglobulin classes in birds in comparison to mammals}

Three classes of immunoglobulins in birds are known. First described is the mammalian IgG which is analogous to IgY and is mainly present in serum and egg yolk [6]. In previous studies, IgY has been called IgG because of its similar function and concentration in the serum. Nowadays, this terminology has been found to be incorrect, due to clear differences in molecular structure. Furthermore, recent studies describe the evolutionary relationship between avian IgY's and human IgE [7]. In addition, IgY's are also found in reptiles, amphibian and lungfish. The comparion of different Immunoglobulin classes are shown in Table 1.

Research has shown that other immunoglobulins including chicken IgA and IgM have similar molecular weight, structure and electrophoretic mobility compared to mammalian IgA and IgM.

IgY antibodies make about $75 \%$ of all immunoglobulins. The serum concentrations of IgY, IgA, and IgM have been reported to be $5.0,1.25$, and $0.61 \mathrm{mgml}^{-1}$, respectively [8].

In spite of functional homology between avian IgY and mammalian IgG, there are differences in molecular weight, structure and biochemical functions. They are composed of two identical heavy and light chains bound together with disulphide bonds. Furthermore, they own a variable antigen-binding-site and a constant highly conserved region. IgY's are distinguished from IgG's with major heavy chains and therefore a higher molecular weight. Moreover, avian IgY has a shorter and thus less flexible hinge region than IgG [9]. It has also been suggested that IgY's have more hydrophobic molecules than IgG antibodies and also have a lower isoelectric point [10].

Table 1 Basic comparison of the adaptive immune system between avian and mammals

\begin{tabular}{llllll}
\hline Vertebrate class & \multicolumn{4}{l}{ Immunoglobulin isotype } \\
\hline Mammals & $\lg M$ & $\lg D$ & $\lg G$ & $\lg \mathrm{E}$ & $\lg \mathrm{A}$ \\
Avian species & $\lg \mathrm{M}$ & & $\lg \mathrm{C}$ & & $\lg \mathrm{P}$ \\
\hline
\end{tabular}

The adaptive immune system of avian and mammals is based on immunoglobulins. Birds produce three types of immunoglobulins ( $\operatorname{lgM}, \lg Y$ and $\lg A)$, and the mammals five $(\lg M, \lg D, \lg G, \lg E$ and $\lg A)$. $\ln$ both cases the acquired immunity includes T-cell receptors (TCRs), polymorphic MHC class I and II molecules, primary and secondary lymphoid organs, rearrangement of the recombination- activating gene (RAG) and antibody class switch
IgY's neither activate the complement system like IgG's [11] nor interact with rheumatoid factors in Immunoassays [10]. The structural differences between IgY's and IgG's are shown in Fig. 1. Furthermore, IgY's do not interfere with protein A or C. This may not simplify the purification but there are several methods for IgY extraction from the egg yolk.

The antibody diversity in chicken is distinguished from mammals and is based on gene conversion and somatic hyperconversion.

\section{Production of IgY's starts with the immunization of chickens}

IgY's are an inexpensive and an alternative form of polyclonal antibodies. For immunization the hens were injected with specific antigens intramuscularly for several intervals. Antibodies are transferred from hen to the offspring via the latent stage of the egg. The immune-incompetent chick is able to resist various infectious diseases due to the innate immune system given from the hen. The transfer of IgY antibodies from maternal serum to the egg yolk is analogous to the cross-placental transmission in mammals [12]. During the last days of the embryonic development phase, IgY is transported across the yolk sac membrane into the embryonic bloodstream [13]. Recent studies show that the transfer of IgY from serum to egg yolk is a receptormediated process which allows a selective transfer of antibodies from the maternal serum $[14,15]$. Research supported that a specific sequence (His-Glu-Ala-Leu: HEAL) in the FC-region and an intact hinge region are required for transport. Changes in this amino acid sequence inhibit IgY transport into the egg yolk. Roughly 4-6 days after inoculation, IgY's can be detected in the egg yolk $[16,17]$.

The antigen dose significantly influences the immune response. Through renewed immunization the concentration of antibodies can be strongly increased in the egg yolk. This process avoids bleeding of animals, stress and permits the harvest of large amounts of antibodies. Furthermore, long-lasting high titre of IgY can be detected in egg yolk [18].

Schade et al. [19] published a review about all IgY extraction and purification methods. The most frequent used processes are with help of polyethyleneglycol [20], ammonium or sodium sulfate [21, 22]. After purification IgY's show a high stability over a few months to a few years under specified conditions [19].

Gene-specific antibodies make the complicated multistep process for specific antigen synthesis redundant [23].

\section{Stability of avian IgY's}

For food fortification and the intestinal treatment to cure or prevent diseases, it is necessary, to improve the heat and $\mathrm{pH}$ resistance of IgY's. Several studies have been conducted to evaluate the stability of these antibodies. The 

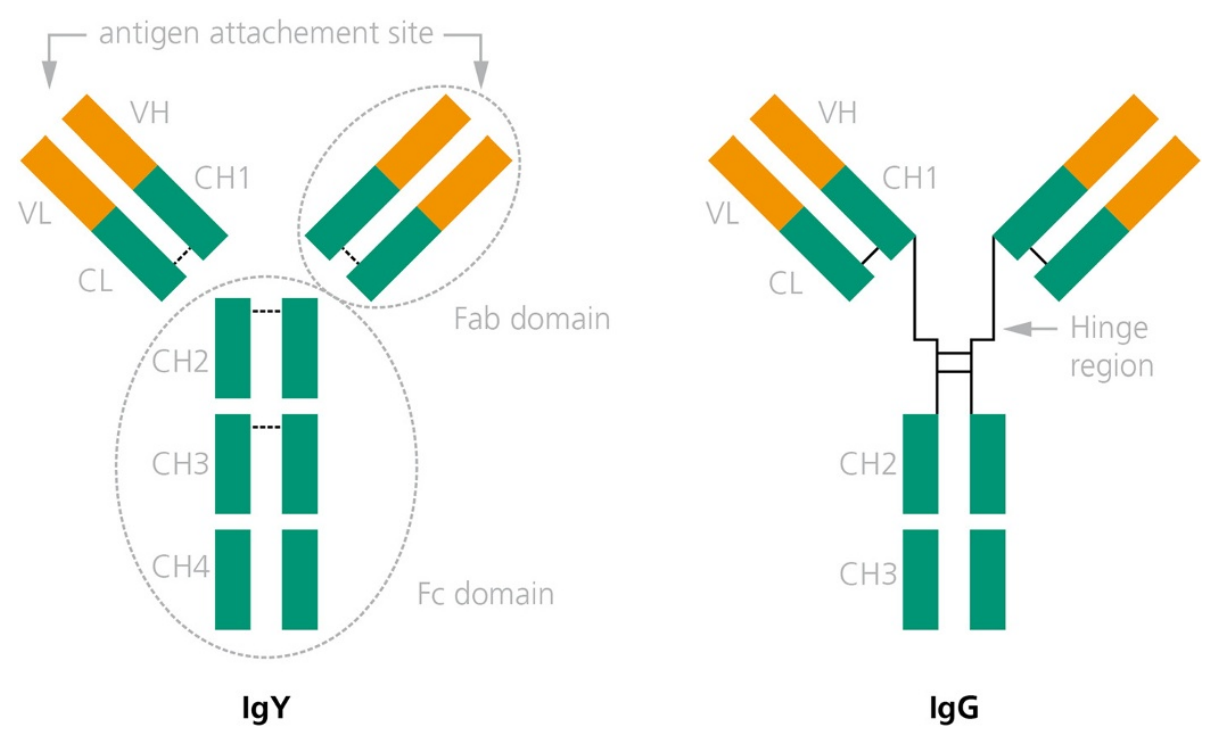

Fig. 1 Structure of avian IgY versus mammalian lgG. Both molecules contain two heavy and two light chains, which consist of a variable domain $(\mathrm{VH}$ and $\mathrm{VL})$ and four constant domains $(\mathrm{CH} 1, \mathrm{CH} 2, \mathrm{CH} 3$ and $\mathrm{CH} 4)$, respectively. IgG has a longer hinge region, which makes it more flexible than avian $\lg Y$

activity of IgY may be reduced by gastric conditions, particularly due to a low $\mathrm{pH}$ value [24]. Chicken antibodies are quite stable against digestive enzymes trypsin and chymotrypsin. Although there is a high loss of activity through Pepsin under low $\mathrm{pH}$ conditions in a short time [24, 25], IgY is stable at $\mathrm{pH} 4-9$ and up to $65^{\circ} \mathrm{C}$ in aqueous conditions. This resembles IgG, which is stable at $\mathrm{pH} 3-10$ and up to $70{ }^{\circ} \mathrm{C}[26,27]$. However, the resistance of IgY to low pH conditions increases if high salt concentrations or stabilizing reagents e.g. sorbitol are present. Xylitol does not have such an effect on heat resistance [28]. Furthermore, the addition of sucrose increases the resistance against low $\mathrm{pH}$ ranges, heat and pressure [29]. The egg yolk may be able to stabilize IgY under low $\mathrm{pH}$ conditions and higher temperatures as well [30]. Several studies also describe protein modifications and coatingmethods, respectively, and their positive effect against inactivation through digestion, heat or acidic conditions. Heat resistance of human IgG antibodies can be increased with help of Polyethyleneglycol-modifications [31]. Encapsulation on IgY's in liposomes has been detected to stabilize antibodies against peptic hydrolysis under acidic conditions [32]. Furthermore, the protective effect of microencapsulation with chitosan-alginate on IgY during gastric passage in vivo has been evaluated [33]. IgY was reported to be stable for an extended durability for 14 weeks except at temperatures over $50{ }^{\circ} \mathrm{C}[30,34]$. Gujral et al. analyzed the IgY antibody stability during 78 weeks of storage at room temperature. In this case a combination with mannitol stabilized the IgY during the extended period [35].

\section{Advantages for using IgY's}

The production of IgY's is a non-invasive alternative to current methods. The keeping of chickens is inexpensive and the animals are easy to handle. It avoids repetitive bleeding and pain of laboratory animals. Furthermore, it is also very effective. The IgY-titre in the egg yolk of immunized chickens remains very high for a long period of time [18]. One egg yolk contains more antibodies compared to the average isolated from the blood of immunized rabbits [36, 37].

IgY's are able to prevent or cure human diseases as described previously. IgY's are not able to pass the gastric barrier [28]. This offers various possibilities for passive immunization in the digestive system against pathogenic viruses and bacteria. But there are further application possibilities, e.g. in diagnostic tests or protein purification processes. IgY's are less acid- and heat resistant than rabbit IgG $[27,38]$. In 2002 Lee has shown that it is possible to stabilize the $\mathrm{pH}$ resistance with the help of sorbitol [28]. A further problem as well is the molecular resistance against proteolytic cleavage during the stomach passage. In 1993, Hatta and colleagues published, that IgY activity was reduced within a short time by pepsin, trypsin and chymotryp$\sin [26]$.

An advantage is that IgY's neither activate the complement system nor bind to protein A and G, rheumatoid factors or cell surface $[9,36]$. The phylogenetic distance between mammals and avian causes a high immune response of birds to mammalian antigens. This increases 
the binding specificity of IgY which is shown through immune diagnostics procedures like immunohistochemistry, ELISAs or immunofluorescence.

\section{IgY antibodies and bacteria}

In 1984 Marshall and Warren firstly described Helicobacter pylori-previously named Campylobacter pylor$i-$ and its association with active chronic gastritis. They characterized the bacterium as a spiral, gram-negative organism with sheathed flagella. The organism is found in the human stomach and induces inflammation of the gastric mucosa [39]. It is known that H. pylori causes chronic gastritis, peptic ulcers, gastric mucosa associated lymphoid tissue (MALT) lymphoma and gastric cancer $[40,41]$. Presently $70 \%$ of all people in the world are infected with $H$. pylori [42]. But only a small number develop pathological symptoms. Previous studies showed that the eradication of $H$. pylori inhibits the reoccurrence of new gastric ulcers, cures several MALTomas and prevents peptic ulcers and gastric cancer [40, 43].

Nowadays the infection with the bacterium can be detected fast and often successfully medicated with specific antibiotic regimes which Wu et al. described in the Review of evidence-based therapies against $H$. pylori. But novel tools are necessary because there is a critical increase of antibiotic resistances.

Previous studies showed a positive effect of specific IgY's against bacterial intoxications. The use of an oral therapy with IgY's offers the possibility of passive immunization. There are several strategies of using IgY's in host protection: a) inhibition of bacterial enzyme activity, b) toxin neutralization, c) blocking cell adhesion of microorganisms. The most effective way for passive immunization is using IgY produced as a response to previously selected characteristic bacterial antigens.

First trials for application of IgY's in neonatal piglets were already conducted in 1998. Threatening enteric infections were treated with specific $\operatorname{IgY}$ antibodies against E. coli K88+ [44]. Later these therapeutic options were also validated with other E. coli, Salmonella, Campylobacter and Rotavirus strains [38, 45-48]. Enteric infections caused by Salmonella are another problem in chicken meat. Chalghoumi and colleagues published a summarized review about the need of alternative methods to prevent enteric infections in 2010. IgY's may be a useful and attractive tool to passively immunize chickens and lower the infection rate in humans after consumption [5].

LeClaire et al. delivered chickens with staphylococcal enterotoxin B (SEB) from Staphylococcus aureus. After immunization they purified the egg yolk and treated rhesus monkeys with the extract. At the same time the monkeys were exposed to a lethal aerosolized dose of
SEB. All animals which were treated with specific antiSEB-IgY survived [49].

The actual transmission of $H$. pylori has never been clarified. The $H$. pylori urease-enzyme may be mainly responsible for colonization of human gastroduodenal mucosa. This enzyme allows the survival in the acidic gastric milieu. Urease creates a neutral microenvironment around the organism. It catalyzes the cleavage of urea to ammonia and carbon dioxide. This immediately increases the ph value and allows the implantation in the mucosa. The organism burrows into the mucosa to reach the epithelial cells where a less acidic environment is present [50]. Developed IgY's against the whole-cell lysate of a $H$. pylori strain inhibit growth and urease activity of the organism in vitro [25]. In 2004 Horie and colleagues demonstrated the efficiency of specific antiurease-IgY in designed drinking yogurt against $H$. pylori infections. They showed that the oral intake of highly specialized antibodies suppress the infection in humans. Due to urease inhibition the adhesion to the mucosa was also inhibited [51]. In 2009 Attallah and his group developed a reliable model for $H$. pylori infection in mice. Most cases of gastritis with inflammatory changes were detected. They developed IgY-antibodies against the cell lysate of a human pathogenic $H$. pylori strain in chicken and treated diseased mice with it. Results demonstrated that the passive immunized mice showed a significant lower degree of infection and gastritis than untreated animals [52]. Oral administration of preformed specific antibodies is an attractive approach against infections of the digestive system in humans and animals $[9,53]$.

\section{Monoclonal IgY-antibodies in gastric cancer therapy}

H. pylori is a significant risk factor for the genesis of gastric cancer. As mentioned above, the eradication inhibits reoccurrence of gastric cancer. Changes in cellular signaling cascades lead to cancer development. Cells proliferate and grow uncontrolled quickly. The reasons for this are somatic mutations leading to permanently activated receptors and over-expression of receptors or ligands. Novel therapies addressed these targets. Monoclonal antibodies which are able to bind epitopes of the extracellular domain of growth factor receptors were able to prevent the receptor-ligand interaction and receptor dimerization. There are possibilities influencing the signal molecules, enzymes and intracellular receptors. The antibodies used at present are chimeric, humanized biological therapeutics [54]. It is conceivable that IgY's administered orally cause no allergic reaction and can be used as a preventative therapy for gastric cancer caused by $H$. pylori or as a general prevention against inflammation caused by this bacteria. Additionally, because of its high stability it can be used as a food supplement, 
which increases the access of this therapeutic tool worldwide [55].

\section{Novel therapies against dental caries and periodontitis} Dental caries are a result of oral bacteria like Streptococcus mutans or Streptococcus sobrinus. To inhibit dental breakdown, a sugarless diet or use of fluoride is recommended. In addition to antibiotics or other antibodies, IgY's can be applied against caries causing bacteria [56]. This was first demonstrated positively in rats [57] and then in humans as well [58].

In addition to caries, periodontitis also plays an important role in dental diseases. Porphyromonas gingivalis may be the main cause for periodontitis [59]. In 2007 it was demonstrated that IgY's against a membrane-protein of $P$. gingivalis inhibits the development of a pathogen biofilm on the teeth surface and probably also following periodontal diseases [60].

\section{New target for egg yolk antibodies: Pseudomonas aeruginosa}

Cystic fibrosis (CF), an autosomal recessive hereditary disease, affects mainly the lungs of patients among other symptoms. Causes are mutations in the gene encoding the cystic fibrosis transmembrane conductance regulator (CFTR) protein [61]. This leads to a reduced transport of chloride from exocrine cells and causes the development of viscous mucus in the bronchia. Chronicle lung infections by the opportunistic bacteria Pseudomonas aeruginosa (PA) are the main causes of morbidity and mortality in CF patients. In 2003, Kollberg and colleagues published that rinsing with a solution of specific anti-PA IgY in the evening may prevent the initial adhesion of the bacteria to the mucosal surface of the oropharynx in CF patients [62]. At the end of their study, all participants in the IgY treated group were still without chronicle PA infections. It was demonstrated that IgY could be used as a possible prophylaxis treatment in CF patients and thus reduces the necessity of frequent applications of antibiotics [62].

\section{IgY's as a new treatment approach for Celiac disease}

Celiac disease (CD) is an autoimmune disease triggered by the ingestion of gluten-containing grains in susceptible individuals. Here, wheat gluten and similar alcohol-soluble proteins are the causes responsible for the development of intestinal damage. The disease is characterized by a loss of absorptive villi and hyperplasia of the crypts. A gluten free diet is currently the only accepted treatment for celiac disease [63]. In 2012 Gujral and colleagues evaluated specific IgY antibodies against gliadin. As previously stated, purified IgY antibodies are extremely sensitive to gastric conditions and are rapidly inactivated by Pepsin under low $\mathrm{pH}$ ranges. The development of appropriate sugar protectants enables neutralization and the adsorption of gliadin in both in vitro and in vivo [35]. This could mean a revolution in the celiac disease treatment regime and harbors new hope for all affected persons.

\section{Conclusion}

Using IgY in disease prevention and outlook

Today IgY technology is a fast spreading field in life sciences. It may not be only a future vision anymore. IgY's in nose spray, cosmetics, body lotions, functional food e.g. yogurt, powder supplement may be able to prevent or cure human diseases. The use of IgY antibodies offers the possibility for reducing antibiotics in the treatment of bacterial infections of the digestive system. In addition, egg yolk antibodies provide a new approach for attending Candida albicans and intestinal parasites as well. Furthermore, IgY treatment promises passive immunization in newborns and immune compromised patients. Patients during chemotherapy do not produce sufficient amounts of antibodies in response to vaccines. In this case passive immunization has provided new opportunities and an alternative to current treatment strategies. It may also be a new approach in therapy for chronic inflammatory bowel diseases e. g. crohn's disease or ulcerative colitis. The local therapy with IgY antibodies in the digestive system could replace the current systemic treatment regime. Furthermore, IgY's promise a new field for all basic prophylactic treatment strategies.

There is a high potential for IgY antibodies in the treatment of a variety of diseases and an even more prospective future.

\section{Competing interests}

TD is the President and CEO of IgY Immune Technologies and Life Sciences Inc. CO is a consultant to IgY Immune Technologies and Life Sciences Inc.

\section{Authors' contributions}

SM, AS, JZ, TD and CO: Contributed to the original plan for the paper, wrote sections of the paper and contributed to draft revisions. All authors read and approved the final manuscript.

\section{Author details}

${ }^{1}$ Fraunhofer Institute for Cell Therapy and Immunology (IZI), Perlickstraße 1, 04103 Leipzig, Germany. ${ }^{2} \mathrm{IgY}$ Immune Technologies and Life Sciences Inc., Thunder Bay, Canada. ${ }^{3}$ Fraunhofer Project Centre for Biomedical Engineering and Advanced Manufacturing, McMaster University, Hamilton, Canada.

Received: 11 March 2015 Accepted: 28 July 2015

Published online: 20 October 2015

\section{References}

1. Glick B, Chang TS, Jaap RG. The bursa of fabricius and antibody production. Poult Sci. 1956;35:224-5.

2. Sharma JM. The structure and function of the avian immune system. Acta Vet Hung. 1997:45:229-38.

3. Carlander D, Stålberg J, Larsson A. Chicken antibodies. Ups J Med Sci. 1999;104:179-89.

4. Janeway CA. Immunologie. 5. Aufl. Heidelberg [u.a.]: Spektrum, Akad Verl. 2002.

5. Chalghoumi R, Beckers $Y$, Portetelle D, Théwis A. Hen egg yolk antibodies (lgY), production and use for passive immunization against bacterial enteric infections in chicken: a review. Biotechnol Agron Soc Environ. 2009;13:295-308. 
6. Leslie GA, Clem LW. Phylogen of immunoglobulin structure and function. 3. Immunoglobulins of the chicken. J Exp Med. 1969;130:1337-52

7. Taylor Al, Fabiane SM, Sutton BJ, Calvert RA. The crystal structure of an avian IgY-Fc fragment reveals conservation with both mammalian $\operatorname{lgG}$ and $\lg \mathrm{E}$. Biochemistry. 2009;48:558-62.

8. Leslie GA, Martin LN. Studies on the secretory immunologic system of fowl III. Serum and secretory lgA of the chicken. J Immunol. 1973;110:1-9.

9. Warr GW, Magor KE, Higgins DA. IgY: clues to the origins of modern antibodies. Immunol Today. 1995;16:392-8.

10. Dávalos-Pantoja L, Ortega-Vinuesa JL, Bastos-González D, Hidalgo-Álvarez R. A comparative study between the adsorption of lgY and lgG on latex particles. J Biomater Sci Polym Ed. 2000;11:657-73.

11. Carlander D, Kollberg $H$, Wejåker $P$, Larsson A. Peroral immunotheraphy with yolk antibodies for the prevention and treatment of enteric infections. Immunol Res. 2000;21:1-6.

12. Rose ME, Orlans E, Buttress N. Immunoglobulin classes in the hen's egg: their segregation in yolk and white. Eur J Immunol. 1974;4:521-3.

13. Kowalczyk K, Daiss J, Halpern J, Roth TF. Quantitation of maternal-fetal IgG transport in the chicken. Immunology. 1985;54:755-62.

14. Mohammed SM, Morrison S, Wims L, Trinh K, Wildeman AG, Bonselaar J, et al. Deposition of genetically engineered human antibodies into the egg yolk of hens. Immunotechnology. 1998;4:115-25.

15. Morrison S, Mohammed SM, Wims L, Trinh K, Etches RJ. Sequences in antibody molecules important for receptor-mediated transport into the chicken egg yolk. Mol Immunol. 2002;38:619-25.

16. Patterson R, Youngner JS, Weigle WO, Dixon FJ. Antibody production and transfer to egg yolk in chickens. J Immunol. 1962;89:272-8.

17. Woolley JA, Landon J. Comparison of antibody production to human interleukin-6 (IL-6) by sheep and chickens. J Immunol Methods. 1995;178:253-65.

18. Gassmann M, Thommes P, Weiser T, Hubscher U. Efficient production of chicken egg yolk antibodies against a conserved mammalian protein. FASEB J. 1990;4:2528-32.

19. Schade R, Calzado EG, Sarmiento R, Chacana PA, Porankiewicz-Asplund J, Terzolo HR. Chicken egg yolk antibodies (IgY-technology): a review of progress in production and use in research and human and veterinary medicine. Altern Lab Anim. 2005;33:129-54.

20. Pauly D, Chacana PA, Calzado EG, Brembs B, Schade R. IgY technology: extraction of chicken antibodies from egg yolk by polyethylene glycol (PEG) precipitation. J Vis Exp. 2011. doi:10.3791/3084.

21. Vega CG, Bok M, Vlasova AN, Chattha KS, Fernández FM, Wigdorovitz A, et al. IgY antibodies protect against human Rotavirus induced diarrhea in the neonatal gnotobiotic piglet disease model. PLoS One. 2012;7, e42788.

22. Akita E, Nakai S. Comparison of four purification methods for the production of immunoglobulins from eggs laid by hens immunized with an enterotoxigenic E. coli strain. J Immunol Methods. 1993;160:207-14.

23. Zhang $W$. The use of gene-specific lgY antibodies for drug target discovery. Drug Discov Today. 2003:8:364-71.

24. Shimizu M, Fitzsimmons RC, Nakai S. Anti-E. coli Immunoglobulin Y isolated from egg yolk of immunized chickens as a potential food ingredient. J Food Sci. 1988;53:1360-8.

25. Shin J, Yang $M$, Nam SW, Kim JT, Myung NH, Bang $W$, et al. Use of egg yolk-derived immunoglobulin as an alternative to antibiotic treatment for control of helicobacter pylori infection. Clin Vaccine Immunol. 2002;9:1061-6.

26. Hatta H, Tsuda K, Akachi S, Kim M, Yamamoto T, Ebina T. Oral passive immunization effect of anti-human rotavirus $\lg Y$ and its behavior against proteolytic enzymes. Biosci Biotechnol Biochem. 1993;57:1077-81.

27. Shimizu M, Nagashima H, Sano K, Hashimoto K, Ozeki M, Tsuda K, et al. Molecular stability of chicken and rabbit immunoglobulin G. Biosci Biotechnol Biochem. 1992:56:270-4.

28. Lee KA, Chang SK, Lee YJ, Jong Hwa L, Koo NS. Acid stability of antihelicobacter pyroli lgY in aqueous polyol solution. J Biochem Mol Biol. 2002;35:488-93.

29. Shimizu M, Nagashima H, Hashimoto K, Suzuki T. Egg Yolk Antibody (lg Y) stability in aqueous solution with high sugar concentrations. J Food Science. 1994;59:763-5.

30. Jaradat ZW, Marquardt RR. Studies on the stability of chicken lgY in different sugars, complex carbohydrates and food materials. Food Agric Immunol. 2000;12:263-72.
31. Suzuki T, Kanbara N, Tomono T, Hayashi N, Shinohara I. Physicochemical and biological properties of poly(ethylene glycol)-coupled immunoglobuling G. Biochim Biophys Acta. 1984;788:248-55.

32. Shimizu M, Miwa Y, Hashimoto K, Goto A. Encapsulation of chicken egg yolk Immunoglobulin G (IgY) by liposomes. Biosci Biotechnol Biochem. 1993:57:1445-9.

33. Li X, Jin L, Uzonna JE, Li S, Liu J, Li H, et al. Chitosan-alginate microcapsules for oral delivery of egg yolk immunoglobulin ( $\lg Y$ ): in vivo evaluation in a pig model of enteric colibacillosis. Vet Immunol Immunopathol. 2009;129:132-6.

34. Jensenius JC, Andersen I, Hau J, Crone M, Koch C. Eggs: conveniently packaged antibodies. Methods for purification of yolk IgG. J Immunol Methods. 1981;46:63-8.

35. Gujral N, Löbenberg R, Suresh M, Sunwoo H. In-vitro and in-vivo binding activity of chicken egg yolk immunoglobulin $Y(\mathrm{lgY})$ against gliadin in food matrix. J Agric Food Chem. 2012;60:3166-72

36. Tini M, Jewell UR, Camenisch G, Chilov D, Gassmann M. Generation and application of chicken egg-yolk antibodies. Comp Biochem Physiol A Mol Integr Physiol. 2002;131:569-74.

37. Kovacs-Nolan J, Phillips M, Mine Y. Advances in the value of eggs and egg components for human health. J Agric Food Chem. 2005;53:8421-31.

38. Lee EN, Sunwoo HH, Menninen K, Sim JS. In vitro studies of chicken egg yolk antibody (IgY) against Salmonella enteritidis and Salmonella typhimurium. Poult Sci. 2002;81:632-41.

39. Marshall B, Warren J. Unidentified curved bacilli in the stomach of patients with gastritis and peptic ulceration. Lancet. 1984;323:1311-5.

40. Malfertheiner P, Megraud F, O'Morain CA, Atherton J, Axon ATR, Bazzoli F, et al. Management of helicobacter pylori infection-the Maastricht IV/ Florence consensus report. Gut. 2012;61:646-64

41. Kusters JG, van Vliet AHM, Kuipers EJ. Pathogenesis of helicobacter pylori infection. Clin Microbiol Rev. 2006;19:449-90.

42. Kayaçetin S, Güreşçi S. What is gastritis? What is gastropathy? How is it classified? Turk J Gastroenterol. 2014;25:233-47.

43. Uemura N, Mukai T, Okamoto S, Yamaguchi S, Mashiba H, Taniyama K, et al. Effect of Helicobacter pylori eradication on subsequent development of cancer after endoscopic resection of early gastric cancer. Cancer Epidemio Biomarkers Prev. 1997;6:639-42.

44. Marquardt RR, Jin L, Kim J, Fang L, Frohlich AA, Baidoo SK. Passive protective effect of egg-yolk antibodies against enterotoxigenic Escherichia coli K88+ infection in neonatal and early-weaned piglets. FEMS Immunol Med Microbiol. 1999;23:283-8.

45. Sunwoo HH, Lee EN, Gujral N, Suresh MR. Growth inhibition of escherichia coli 987P by neutralizing IgY antibodies. Open Immunol J. 2010;3:1-8.

46. Sunwoo HH, Nakano T, Dixon WT, Sim JS. Immune responses in chickens against lipopolysaccharide of escherichia coli and salmonella typhimurium. Poult Sci. 1996;75:342-5.

47. Sarker SA, Casswall TH, Juneja LR, Hoq E, Hossain I, Fuchs GJ, et al. Randomized, placebo-controlled, clinical trial of hyperimmunized chicken egg yolk immunoglobulin in children with rotavirus diarrhea. J Pediatr Gastroenterol Nutr. 2001;32.

48. Tsubokura K, Berndtson E, Bogstedt A, Kaijser B, Kim M, Ozeki M, et al. Oral administration of antibodies as prophylaxis and therapy in Campylobacter jejuni-infected chickens. Clin Exp Immunol. 1997;108:451-5.

49. LeClaire RD. Protection against bacterial superantigen staphylococcal enterotoxin B by passive vaccination. Infect Immun. 2002;70:2278-81.

50. Amieva MR, El-Omar EM. Host-bacterial interactions in helicobacter pylori infection. Gastroenterology. 2008;134:306-23.

51. Horie K, Horie N, Abdou AM, Yang J, Yun S, Chun H, et al. Suppressive effect of functional drinking yogurt containing specific egg yolk immunoglobulin on helicobacter pylori in humans. J Dairy Sci. 2004;87:4073-9

52. Attallah AM, Abbas AT, Ismail H, Abdel-Raouf M, El-Dosoky I. Efficacy of passive immunization with $\lg Y$ antibodies to a $58-\mathrm{kDa} \mathrm{H}$. pylori antigen on severe gastritis in BALB/C mouse model. J Immunoassay Immunochem. 2009;30:359-77.

53. Yolken RH, Leister F, Wee SB, Miskuff R, Vonderfecht S. Antibodies to rotaviruses in chickens' eggs: a potential source of antiviral immunoglobulins suitable for human consumption. Pediatrics. 1988;81:291-5

54. Kasper S, Schuler M. Targeted therapies in gastroesophageal cancer. Eur J Cancer. 2014;50:1247-58 
55. Rahman S, Nguyen S, Icatlo F, Umeda K, Kodama Y. A novel solution for prevention and treatment of alimentary tract diseases. Hum Vaccines Immunotherapeutics. 2013;9(5):1039-48.

56. Koga T, Oho T, Shimazaki Y, Nakano Y. Immunization against dental caries, Vaccine. 2002;20:2027-44.

57. Otake S, Nishihara Y, Makimura M, Hatta H, Kim M, Yamamoto T, et al. Protection of rats against dental caries by passive immunization with hen-egg-yolk antibody (lgY). J Dent Res. 1991;70:162-6.

58. Hatta H, Tsuda K, Ozeki M, Kim M, Yamamoto T, Otake S, et al. Passive immunization against dental plaque formation in humans: effect of a mouth rinse containing egg yolk antibodies (IgY) specific to streptococcus mutans. Caries Res. 1997;31:268-74.

59. Holt SC, Kesavalu L, Walker S, Genco CA. Virulence factors of porphyromonas gingivalis. Periodontol 2000. 1999;20:168-238.

60. Hamajima S, Maruyama M, Hijiya T, Hatta H, Abiko Y. Egg yolk-derived immunoglobulin ( $\mathrm{lg} Y$ ) against Porphyromonas gingivalis 40-kDa outer membrane protein inhibits coaggregation activity. Arch Oral Biol. 2007:52:697-704.

61. Rommens JM, lannuzzi MC, Kerem B, Drumm ML, Melmer G, Dean M, et al. Identification of the cystic fibrosis gene: chromosome walking and jumping. Science. 1989;245:1059-65.

62. Kollberg $H$, Carlander D, Olesen $H$, Wejåker $P$, Johannesson $M$, Larsson A. Oral administration of specific yolk antibodies (IgY) may prevent Pseudomonas aeruginosa infections in patients with cystic fibrosis: a phase I feasibility study. Pediatr Pulmonol. 2003:35:433-40.

63. Chand N, Mihas AA. Celiac disease: current concepts in diagnosis and treatment. J Clin Gastroenterol. 2006:40:3-14

\section{Submit your next manuscript to BioMed Central and take full advantage of:}

- Convenient online submission

- Thorough peer review

- No space constraints or color figure charges

- Immediate publication on acceptance

- Inclusion in PubMed, CAS, Scopus and Google Scholar

- Research which is freely available for redistribution 